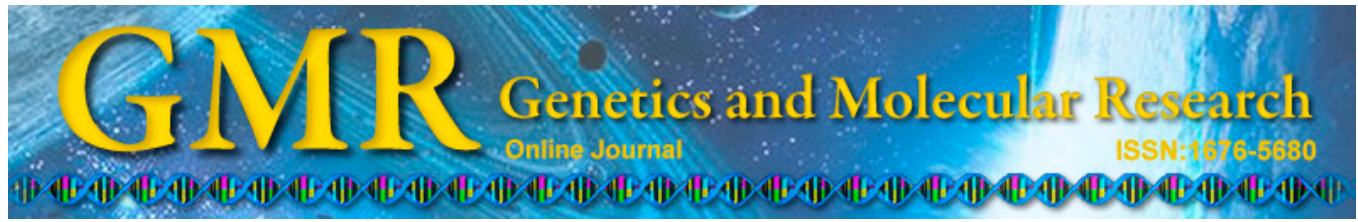

\title{
Correlation of forkhead box transcription factor 01 and myosin heavy chain isoforms in porcine skeletal muscle
}

\author{
X.E. Shi, Z.Y. Song, Q.M. Yang, Y.G. Liu and G.S. Yang \\ Laboratory of Animal Fat Deposition and Muscle Development, \\ College of Animal Science and Technology, Northwest A\&F University, \\ Yangling, Shaanxi Province, China \\ Corresponding author: G.S. Yang \\ E-mail: gsyang999@hotmail.com
}

Genet. Mol. Res. 13 (4): 10231-10240 (2014)

Received January 9, 2014

Accepted November 18, 2014

Published December 4, 2014

DOI http://dx.doi.org/10.4238/2014.December.4.18

\begin{abstract}
We examined the expression of myosin heavy chain (MyHC) isoforms and forkhead box transcription factor O1 (FoxO1) in porcine soleus and extensor digitorum longus (EDL) muscles to clarify the correlation of FoxO1 and the relative abundance of transcripts of MyHC isoforms. Soleus muscle was found to be redder than EDL muscles in pigs, and immunohistochemical fast MyHC staining showed more oxidative type I fibers compared to EDL. qRT-PCR quantification of MyHC isoforms I, IIa, IIx, and IIb showed that expression of MyHC I and MyHC IIa mRNAs was much higher, whereas expression of MyHC IIx and MyHC IIb mRNAs was much lower in porcine soleus muscle compared to EDL muscle. Expression of FoxO1 mRNA and p-FoxO1 protein was significantly more abundant in porcine soleus muscle compared to EDL muscle. The expression of phosphorylated FoxO1 (p-FoxO1) was positively correlated with the expression of MyHC I $(\mathrm{R}=0.9747, \mathrm{P}<0.01)$ and negatively correlated with the expression of MyHC IIx $(\mathrm{R}=-0.9963, \mathrm{P}<0.01)$ and MyHC IIb $(\mathrm{R}=-0.9834, \mathrm{P}<$
\end{abstract}


0.01). Taken together, these results suggested that FoxO1 may play a pivotal role in the determination of muscle fiber type.

Key words: FoxO1; MyHC isoforms; Skeletal muscle; Porcine

\section{INTRODUCTION}

Skeletal muscle is composed of individual muscle fibers. The diversity of skeletal muscle fiber types is explained, in part, by different isoforms of myosin heavy chain (MyHC). MyHC isoforms I, IIa, IIx, and IIb are expressed in skeletal muscle of adult pigs (Lefaucheur et al., 2002). Skeletal muscle is a dynamic tissue and reacts to external cues by changing its metabolism and contractile ability. Transition of MyHC follows a sequential reversible pathway (Pette and Staron, 2000): I $\leftrightarrow$ IIa $\leftrightarrow$ IIx $\leftrightarrow$ IIb.

Importantly, the proportions, structure and functional properties of different muscle fibers affect the growth performance of the animal and are endogenous factors for postmortem meat quality traits (Lengerken et al., 1994). Dramatic improvement of growth performance and lean content of pigs is suspected to coincide with altered meat quality. The inconsistency of results regarding the relationship of muscle fiber traits and meat quality and muscularity demonstrates the difficulty in determining the most advantageous muscle fiber type(s) (Lefaucheur et al., 2004).

The O subfamily of Forkhead/winged helix transcription factors (FoxO) plays an important role in tumor suppression, energy metabolism, and lifespan extension by upregulating target genes involved in cell cycle arrest, apoptosis, energy metabolism, oxidative stress resistance, and muscle atrophy (Daitoku and Fukamizu, 2007; Southgate et al., 2007; Salih and Brunet, 2008). Phosphorylation of the FoxO transcription factors inhibits their action by shuttling them away from the nucleus to the cytosol (Van der Heide et al., 2004). Furthermore, FoxO1, $-3 \mathrm{a}$, and -4 are expressed in skeletal muscle and regulate muscle metabolism and proteolysis in myogenic processes (Gross et al., 2008). In addition, FoxO1 can modulate cell differentiation and stimulate myotube fusion of primary mouse myoblasts (Bois and Grosveld, 2003). However, the physiological role of FoxO1 in skeletal muscle is still unclear. Meanwhile, FoxO1 skeletal muscle transgenic mice show a marked decrease in skeletal muscle mass, and the expression of slow fiber genes but not fast fiber genes are decreased (Kamei et al., 2004). Reciprocally, conditional ablation of FoxO1 expression in the soleus muscle leads to reduced slow fiber and increased fast fiber formation (Kitamura et al., 2007). It seems to be controversial how FoxO1 plays a critical role in muscle fiber-type composition postnatally. Therefore, the effects of FoxO1 on the muscle fiber-type specification still need to be clarified.

In the present study, the expression of MyHC mRNA was examined in the soleus and extensor digitorum longus (EDL) muscles of the adult pig. To complete our study, expression of FoxO1 mRNA and protein p-FoxO1 was examined in porcine soleus and EDL muscles, and the correlation of p-FoxO1 and MyHCs was analyzed.

\section{MATERIAL AND METHODS}

\section{Animals}

Six Duroc x Landrace $\mathrm{x}$ Large white pigs (castrated males) (body weight $=19.50 \pm$ $1.125 \mathrm{~kg}$ ) were placed in individual pens and fed the same diet on the experimental farm of 
the Northwest A\&F University (Yangling, Shaanxi, China), and slaughtered when their weight reached $100 \mathrm{~kg}$ in a local abattoir after a fasting period of $24 \mathrm{~h}$. Pigs were stunned with low voltage tongs. Five minutes after bleeding, samples of the EDL and soleus muscles were excised, placed in plastic cups, immediately frozen in liquid nitrogen and subsequently stored at $-80^{\circ} \mathrm{C}$ until use. The laboratory procedures used in this study conformed to the guidelines of the Northwest A\&F University Animal Care Committee.

\section{Immunohistochemical analysis}

Frozen serial muscle sections from EDL and soleus muscles were air-dried at room temperature for $30 \mathrm{~min}$ and then fixed in ice-cold acetone for $6 \mathrm{~min}$. Sections were washed briefly in PBS and blocked in 5\% goat serum for $30 \mathrm{~min}$, followed by incubation with mouse anti-MYH1/2/4 (MY-32) (Santa Cruz, USA) in 5\% goat serum at room temperature for $2 \mathrm{~h}$. After three washes ( $5 \mathrm{~min}$ each), biotinylated secondary antibodies in PBS were applied to the sections for $1 \mathrm{~h}$ at room temperature. Micrographs were taken using a Leica DMI6000 B microscope (Leica, Germany) equipped with a Photometrics Cool-SNAP camera.

\section{Quantitative real-time RT-PCR (qRT-PCR)}

Muscle tissue was homogenized and total RNA was extracted by standard techniques using TRIzol reagent (Invitrogen, USA). The integrity of the RNA was examined by electrophoresis on $2 \%$ agarose gels, and the concentration was estimated by measuring the absorbance at $260 \mathrm{~nm}$ in a spectrophotometer. A 2- $\mu \mathrm{g}$ sample of total RNA was reverse transcribed to synthesize cDNA using the PrimeScript RT-reagent kit (TaKaRa, Japan) for RT-PCR after treatment with DNase I (TaKaRa) to remove any contaminating genomic DNA. Real-time PCR amplification was done with the iQ5 real-time PCR detection system (BioRad, USA) using SYBR Premix Ex Taq ${ }^{\mathrm{TM}}$ (TaKaRa). Quantification of mRNA was done by the comparative threshold cycle $\left(\Delta \Delta \mathrm{C}_{\mathrm{t}}\right)$ method, except the relative efficiency of each primer was included in the calculation. The specificity of the PCR amplification was always verified by analysis of melting curves. Details of the primers are given in Table 1.

\begin{tabular}{|c|c|c|c|c|c|}
\hline Gene & Primer sequence $\left(5^{\prime}-3^{\prime}\right)$ & $\begin{array}{l}\text { Production } \\
\text { size (bp) }\end{array}$ & $\begin{array}{c}\text { No. } \\
\text { of cycles }\end{array}$ & $\operatorname{Tm}\left({ }^{\circ} \mathrm{C}\right)$ & $\begin{array}{l}\text { GenBank } \\
\text { accession No }\end{array}$ \\
\hline$\beta$-Actin & $\begin{array}{l}\text { GCGGCATCCACGAAACTAC } \\
\text { TGATCTCCTTCTGCATCCTGTC }\end{array}$ & 138 & 27 & 60 & NM007393 \\
\hline FoxO1 & $\begin{array}{l}\text { GCAAATCGAGTTACGGAGGC } \\
\text { AATGTCATTATGGGGAGGAGAGT }\end{array}$ & 95 & 27 & 60 & NM214014 \\
\hline $\mathrm{MyHCI}$ & $\begin{array}{l}\text { AAGGGCTTGAACGAGGAGTAGA } \\
\text { TTATTCTGCTTCCTCCAAAGGG }\end{array}$ & 87 & 27 & 60 & AB053226 \\
\hline MyHCIIa & $\begin{array}{l}\text { GCTGAGCGAGCTGAAATCC } \\
\text { ACTGAGACACCAGAGCTTCT }\end{array}$ & 91 & 28 & 60 & AB025260 \\
\hline MyHCIIb & $\begin{array}{l}\text { ATGAAGAGGAACCACATTA } \\
\text { TTATTGCCTCAGTAGCTTG }\end{array}$ & 125 & 26 & 53 & AB025261 \\
\hline MyHCIIx & $\begin{array}{l}\text { AGAAGATCAACTGAGTGAACT } \\
\text { AGAGCTGAGAAACTAACGTG }\end{array}$ & 154 & 28 & 56 & AF102857 \\
\hline
\end{tabular}




\section{Western blot analysis}

Protein was extracted from the tissue in lysis buffer $(50 \mathrm{~mm}$ Tris- $\mathrm{HCl}, 0.5 \%$ Triton X-100, 2 mM EDTA, $150 \mathrm{mM} \mathrm{NaCl}, \mathrm{pH} 7.5$ ), containing PMSF as previously described (Lin et al., 2007). Protein content was measured as described elsewhere (Fryer et al., 1986). Samples containing $50 \mu \mathrm{g}$ total protein were electrophoresed in SDS-12\% polyacrylamide gel under reducing conditions, followed by electrotransfer onto nitrocellulose membranes. After blocking in 5\% defatted milk in Tris-buffered saline with Tween 20 for $2 \mathrm{~h}$ at room temperature, the membranes were reacted with anti-FoxO1 (Santa Cruz), anti-p-FoxO1 (Ser256) (Bioworld, USA), and anti- $\beta$-actin (Santa Cruz) antibodies for $24 \mathrm{~h}$ at $4{ }^{\circ} \mathrm{C}$. This was followed by incubation for $1 \mathrm{~h}$ at room temperature with horseradish peroxidase-conjugated secondary antibodies and then protein bands were visualized with chemiluminescence reagents (Millipore, Bedford, MA, USA) and quantified using the Image J program (National Institutes of Health, Bethesda, MD, USA).

\section{Statistical analysis}

All statistical analysis was done with the SPSS 13.0 statistical software package. Data are reported as means $\pm \mathrm{SE}$ and analyzed by one-way analysis of variance (ANOVA). The level of statistical significance was set at $\mathrm{P}<0.05$. Linear relationships between the ratio $\mathrm{p}-\mathrm{FoxO}$ / total FoxO1 and MyHC mRNA expression were tested using the Pearson correlation coefficient.

\section{RESULTS AND DISCUSSION}

\section{Muscle fiber composition in porcine soleus and EDL muscles}

Traditionally, skeletal muscle can be distinguished as red and white fibers. In animal production for meat, meat color and tenderness are closely associated with a predominance of red fibers (Chang, 2007). This study showed that porcine soleus muscle is redder than EDL muscle (Figure 1A, B), and increased oxidative type I fibers in porcine soleus muscle were shown by immunohistochemical staining (Figure 1C), in agreement with an earlier report (Lefaucheur et al., 2004).

Morphological, functional and metabolic characteristics of vertebrate skeletal muscles are related mainly to the muscle fiber types characterized mainly by the isoforms of MyHC that they contain (Cobos et al., 2001). Mammalian myofibers are classified on the basis of MyHC type into types I, IIa, IIb, and IIx, with types I and IIa exhibiting oxidative metabolism and types IIb and IIx being primarily glycolytic (Schiaffino and Reggiani, 1996). Type I fibers are also termed slow fibers because of the slow rate of contraction owing to the low level of ATPase activity associated with type I MyHC and can remain contracted for lengthy periods. By contrast, type II fibers contract quickly and fatigue rapidly (Bassel-Duby and Olson, 2006).

Quantification of RNA expression may be a more valuable technique for identifying changes in MyHC expression (Jankala et al., 1997). SYBR green real-time RT-PCR RNA analysis demonstrated a high degree of sensitivity when applied to the expression of genes selected from small amounts and limited tissue samples. A major determinant of skeletal muscle physiology is MyHC expression. Our results for MyHC composition showed MyHC I expression in soleus, while MyHC IIb expression was present in EDL muscles (Table 2). 
Furthermore, the expression of MyHC I and MyHC IIa mRNAs was much higher in porcine soleus muscle compared to EDL muscle, whereas the expression of MyHC IIx and MyHC IIb mRNAs was higher in porcine EDL (Figure 2). These results are in good agreement with earlier work (Lefaucheur et al., 2004; Li et al., 2010), but the expression of the mRNA of different isoforms showed some important differences in relation to reports for other animal species. Fibers from mouse soleus muscle cover the spectrum from MyHCI to MyHC I, IIa and IIx, whereas EDL muscles have fibers from MyHC IIx to type MyHC IIb (Calderón et al., 2010). MyHCI, IIa, IIx, and IIb mRNA transcripts and protein isoforms are present in rat EDL muscle (Vadászová et al., 2006). Cat limb muscles have two types of fast fibers (MyHC IIx and IIb) and one type of slow fiber, which express MyHC IIx, IIa and I, respectively (Lucas et al., 2000). MyHC isoforms I, IIa and IIx have been detected at both the protein and mRNA levels in sheep skeletal muscle (Hemmings et al., 2009). MyHC IIb has been detected at the mRNA level in sheep muscle (Vuocolo et al., 2007), but it is not clear whether the protein is expressed. MyHC IIb mRNA but not the protein has been detected in certain human muscle fibers (Horton et al., 2001).

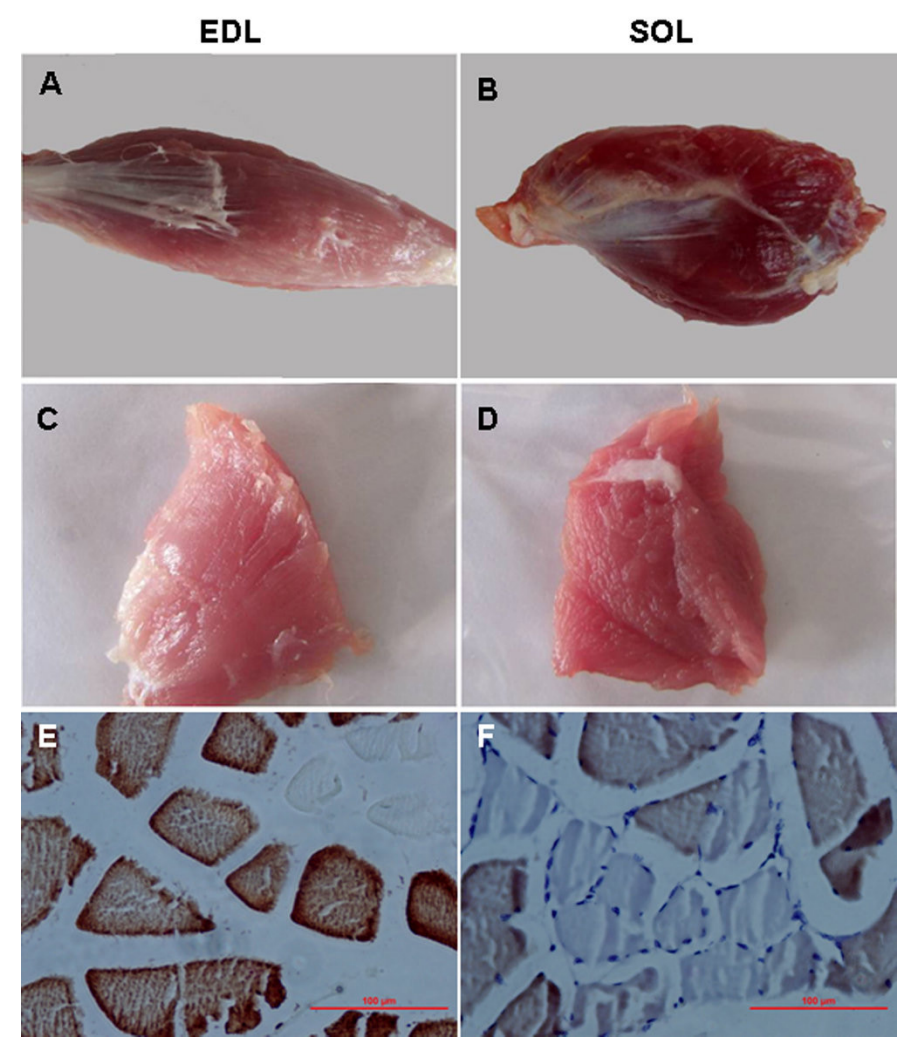

Figure 1. Comparison of representative samples of dissected EDL and soleus muscles in pig. The samples were excised from Duroc x Landrace x Large white (castrated males) pigs (weight $100 \mathrm{~kg}$ ). Soleus muscles were redder than EDL muscles (A and B). A) Total EDL and soleus muscles. B) Transverse sections of EDL and soleus muscles. Expression of fast $\mathrm{MyHC}$ in pig EDL and soleus muscles $\mathbf{C}$ ). Immunohistochemical analysis of fast MyHC protein in pig EDL and soleus muscles. Muscle fibers that contain fast MyHC are stained brown using diaminobenzidine. Bar $=100 \mu \mathrm{m}$. 
Table 2. Comparision of myosin heavy chain mRNA isoforms within EDL or soleus muscles by real time PCR.

\begin{tabular}{lcc}
\hline MyHC isoform & EDL & Soleus \\
\hline MyHCI & $1.00 \pm 0.77^{\mathrm{b}}$ & $1.00 \pm 0.04^{\mathrm{a}}$ \\
MyHCIIa & $3.11 \pm 0.64^{\mathrm{b}}$ & $0.07 \pm 0.02^{\mathrm{b}}$ \\
MyHCIIb & $7.08 \pm 0.73^{\mathrm{b}}$ & $0.02 \pm 0.01^{\mathrm{b}}$ \\
MyHCIIx & $88.81 \pm 0.87^{\mathrm{a}}$ & $0.01 \pm 0.01^{\mathrm{b}}$ \\
\hline
\end{tabular}

Different letters show significant differences in the same column $(\mathrm{P}<0.05)$, same superscript letters do not show significant differences in the same column $(\mathrm{P}<0.05)$.
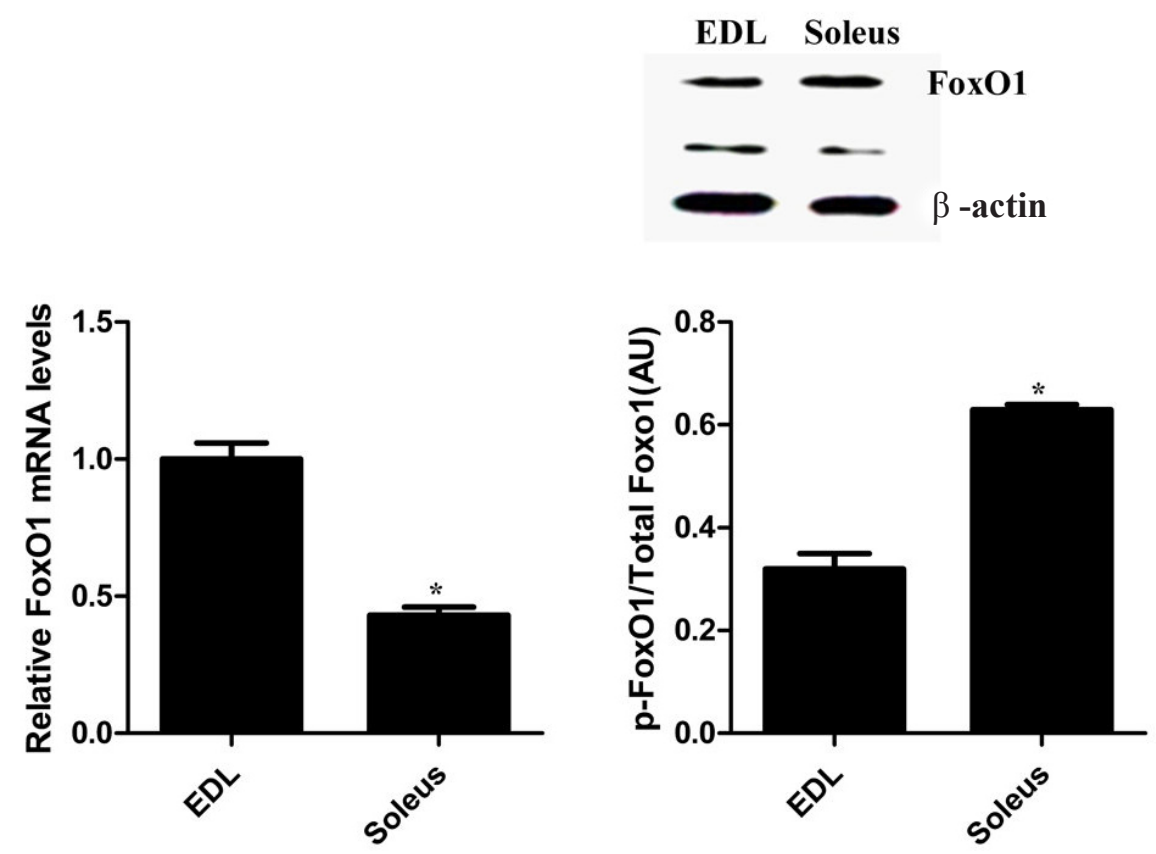

Figure 2. Comparision of relative mRNA expression levels of MyHCs between EDL and soleus muscles. The statistical data of MyHC I (A), MyHC IIa (B), MyHC IIx (C), and MyHC IIb (D) mRNA expression. Total RNA was extracted using TRIzol reagent (Invitrogen, USA). Two-microgram sample of total RNA was reverse transcribed to synthesize cDNA using the PrimeScript RT-reagent Kit (TaKaRa, Japan). Real-time PCR was performed using a kit from TaKaRa and specific primer for MyHCs. Quantification of the mRNA was done by the comparative threshold cycle $(\Delta \Delta \mathrm{Ct})$ method. $\beta$-actin was used as internal control and total RNA $(1 \mathrm{mg})$ was shown as a representative of equal total RNA loading. The asterisk indicates significant difference of mRNA expressions in corresponding tissues $(\mathrm{P}<0.05)$ between EDL and soleus muscles $(\mathrm{N}=6$ /group).

\section{Expression and phosphorylation of FoxO1}

To investigate whether FoxO1 is correlated with fiber type, the expression of FoxO1 was examined in muscles that differ in their predominant fiber type. We found that expression of FoxO1 mRNA in pigs was significantly lower in soleus muscles compared to EDL muscles (Figure 3A), which is in good agreement with earlier study (Yang et al., 2008). This result showed that FoxO1 may be involved in the transformation of muscle fiber type. In addition, FoxO activity is controlled by altering an intricate combination of post-translational 
modifications of FoxO, such as phosphorylation, acetylation, ubiquitination, and methylation, which in turn regulate subcellular localization, protein levels, DNA-binding properties, and transcriptional activity (Calnan and Brunet, 2008). The transcriptional regulatory functions of FoxO proteins require nuclear localization. Export from the nucleus to the cytoplasm is regulated by the phosphorylation of FoxO, interfering with FoxO transcriptional activities (Vogt et al., 2005). Thus, we examined the expression of p-FoxO1 protein in porcine muscles in this study. The results showed that the expression of p-FoxO1 was notably higher in porcine soleus muscle compared to EDL muscles (Figure 3B, C and D). These results indicated that FoxO1 is closely related to muscle fiber type.
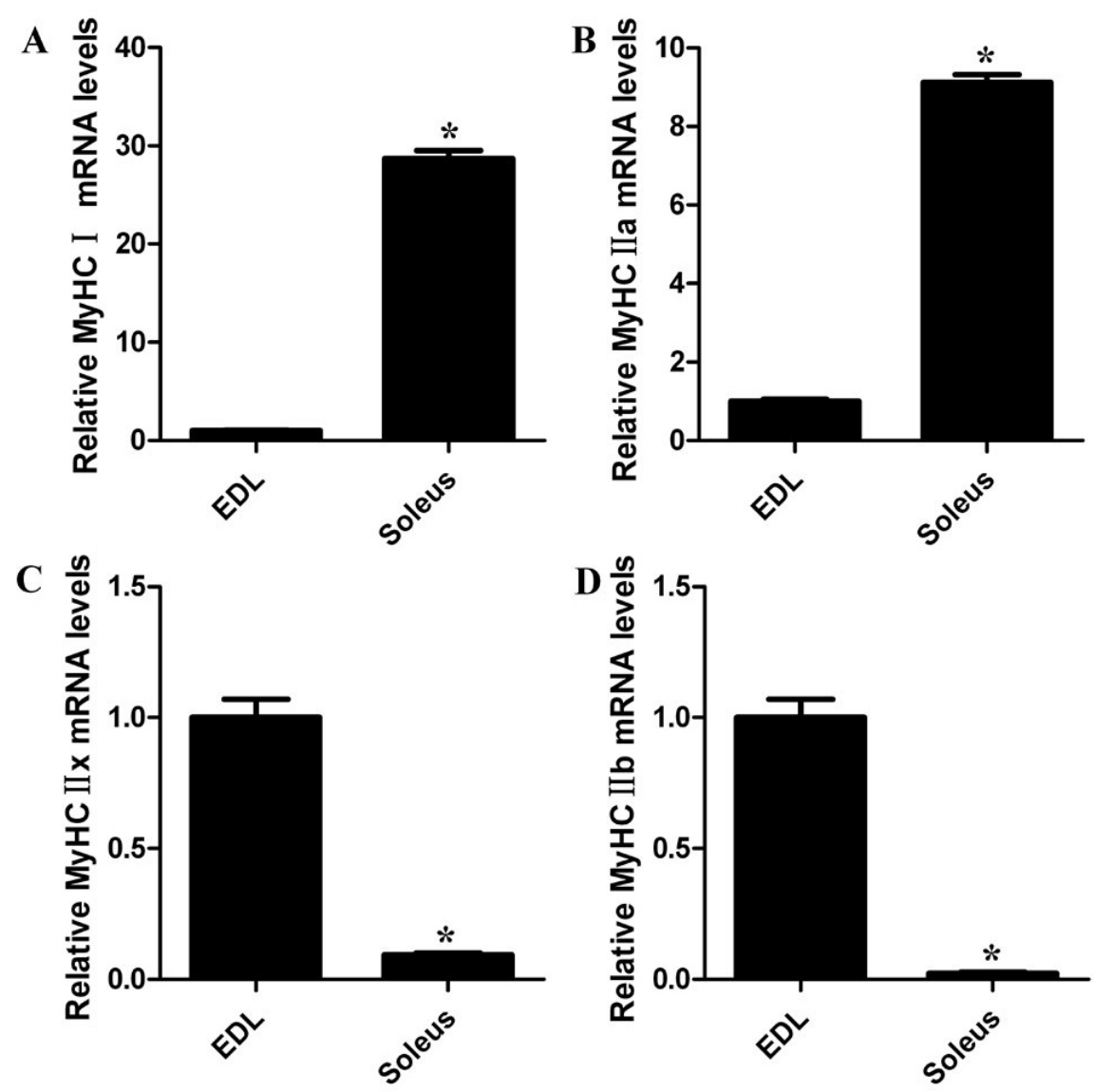

Figure 3. FoxO1mRNA expression and protein content in pig EDL and soleus muscles. The real-time PCR was performed to detect the expressions of FoxO1mRNA (A) and Western blot was performed to assess total FoxO1 (B), phorphorylation of FoxO1 at Ser256 (C) in pig EDL and soleus muscles. Total RNA was extracted using TRIzol reagent (Invitrogen, USA). Two-microgram sample of total RNA was reverse transcribed to synthesize cDNA using the PrimeScript RT-reagent Kit (TaKaRa, Japan). Real-time PCR was performed using a kit from TaKaRa and specific primer for FoxO1. Quantification of the mRNA was done by the comparative threshold cycle $(\Delta \Delta \mathrm{Ct})$ method. $\beta$-actin was used as internal control and total RNA $(1 \mathrm{mg})$ was shown as a representative of equal total RNA loading. $\beta$-actin was used as internal control for protein loading. Values are reported as means $\pm \mathrm{SE}$. The asterisk indicates significant difference $(\mathrm{P}<0.05)$ between $\mathrm{EDL}$ and soleus muscles $(\mathrm{N}=6 /$ group$)$. 


\section{Correlation of FoxO1 and MyHCs in porcine soleus and EDL muscles}

Earlier reports suggested that it is possible to transform oxidative fibers into glycolytic fibers and vice-versa (Pette and Staron, 2001). The relationship between FoxO1 expression and muscle fiber type is complicated by the fact that FoxO1 appears to influence fiber type. Thus, expression of FoxO1 was examined in porcine soleus and EDL muscles. We found that expression of $\mathrm{p}$-FoxO1 was negatively correlated with MyHC I $(\mathrm{R}=0.9747, \mathrm{P}<0.01)$ whereas positively correlated with MyHC IIx $(\mathrm{R}=-0.9963, \mathrm{P}<0.01)$ and MyHC IIb $(\mathrm{R}=$ $-0.9834, \mathrm{P}<0.01$ ) in pigs (Table 3). These results further suggest that FoxO1 is concerned with muscle fiber types. In vivo studies have shown FoxO1-transgenic mice to have decreased skeletal muscle mass and expression of type I (slow twitch/red muscle) fiber genes (Kamei et al., 2004). Inhibition of the PI3K (phosphatidylinositol 3-kinase)/PKB (protein kinase B) and MAPK (mitogen-activated protein kinase)/ERK (extracellular signal-regulated kinase) pathways causes activation of FoxO transcription factor in pancreatic cancer (Roy et al., 2010).

$\begin{aligned} & \text { Table 3. Correlation analysis of the phosphorylation level of FoxO1 and MyHC isoforms in pig EDL and } \\
& \text { soleus muscles. }\end{aligned}$
\begin{tabular}{lc}
\hline MyHC isoform & p-FoxO1/total FoxO1 \\
\hline MyHC I & $0.9747^{*}$ \\
MyHC II a & -0.9193 \\
MyHC II x & $-0.9963^{*}$ \\
MyHC II b & $-0.9834^{*}$ \\
\hline
\end{tabular}

The asterisk indicates extremely significant difference $(\mathrm{P}<0.01)(\mathrm{N}=6 /$ group$)$.

Overexpression of ERK2 induces the fast fiber type program in the slow-contracting soleus muscles. MAPK signaling, most likely to be the ERK1/2 pathway, is necessary to preserve the fast-twitch fiber phenotype with a concomitant repression of the slow-twitch fiber program (Shi et al., 2008). MAPK/ERK2 phosphorylates IP3R1 at least at one highly conserved site, and its mutation abrogates IP3R1 phosphorylation in this domain (Lee et al., 2006). IP3R1 activity regulates expression of the muscle fiber type-specific gene in innervated muscle fibers (Jordan et al., 2005). These results indicate that PI3K/PKB and MAPK/ ERK pathways boost the formation of slow muscle fibers by inhibiting FoxO1. In addition, the transcription of slow and fast $\mathrm{MyHC}$ genes uses different combinations of nuclear factor of activated T cells (NFAT) family members, ranging from MyHC-slow, which uses all four NFAT isoforms, to MyHC IIb, which uses only NFATc4 (Calabria et al., 2009). Inhibition of the calcineurin/NFAT signaling cascade by FoxO and release of this repressive action by the PI3K/PKB pathway are important mechanisms whereby FoxO factors govern cell growth in cardiac muscles (Ni et al., 2006). These studies also illustrate that FoxO may affect muscle fiber types by cascading calcineurin/NFAT signaling. Treatment of wild-type mice with peroxisome proliferator-activated receptor $\delta$ (PPAR $\delta$ ) agonist elicited a similar type I fiber gene expression profile in muscles (Wang et al., 2004). Skeletal muscles from ovariectomized mice display decreased PPAR $\delta$ and FoxO1 expression, and gene expression profiles indicate fewer type I oxidative fibers (Rogers et al., 2010). In brief, these results show indirectly that FoxO1 may have a pivotal role in determining skeletal muscle fiber type, but further study is needed to determine whether FoxO1 affects the conversion of muscle fiber types. 


\section{CONCLUSION}

In summary, the results of this study indicate that porcine skeletal muscle fibers can be classified into four types at the molecular level, according to the isoform of MyHC present in each fiber (MyHC I, IIa, IIx, and IIb). Expression of MyHC I is predominant in porcine soleus muscles, whereas expression of MyHC IIb is predominant in EDL muscles. The expression of FoxO1 mRNA in the porcine soleus muscles is lower than that in the EDL muscles; whereas the ratio of phosphorylated FoxO1/total FoxO1 protein in the porcine soleus muscles is higher than that in the EDL muscles. The expression of p-FoxO1 is positively correlated with the expression of MyHC I $(\mathrm{R}=0.9747, \mathrm{P}<0.01)$ and negatively correlated with the expression of MyHC IIx $(\mathrm{R}=-0.9963, \mathrm{P}<0.01)$ and MyHC IIb $(\mathrm{R}=-0.9834, \mathrm{P}<0.01)$ in pigs. Thus, FoxO1 likely regulates MyHC I negatively and MyHC IIx and MyHC IIb positively. As for the analysis of FoxO1 and muscle fiber type, further research is needed.

\section{Conflict of interest}

The authors declare there is no conflict of interest.

\section{ACKNOWLEDGMENTS}

Research supported by the National Natural Science Foundation of China (Grant \#31272410), the Scientific and Technological Innovation Project for Youths of Northwest A\&F University (Grant \#ZD2012007), the Program for Innovative Research Team in the Northwest A\&F University, and the National Swine Industry Technology System (Grant \#CARS-36-04B).

\section{REFERENCES}

Bassel-Duby R and Olson EN (2006). Signaling pathways in skeletal muscle remodeling. Ann. Rev. Biochem. 75: 19-37. Bois PR and Grosveld GC (2003). FKHR (FOXO1a) is required for myotube fusion of primary mouse myoblasts. EMBO J. 22: 1147-1157.

Calabria E, Ciciliot S, Moretti I, Garcia M, et al. (2009). NFAT isoforms control activity-dependent muscle fiber type specification. PNAS. 106: 13335-13340.

Calderón JC, Bolaños $\mathrm{P}$ and CaputoC (2010). Myosin heavy chain isoform composition and $\mathrm{Ca}^{2+}$ transients in fibres from enzymatically dissociated murine soleus and extensor digitorum longus muscles. J. Physiol. 588: 267-279.

Calnan DR and Brunet A (2008). The FoxO code. Oncogene 27: 2276-2288.

Chang KC (2007) Key signalling factors and pathways in the molecular determination of skeletal muscle phenotype. Animal 1: 681-698.

Cobos AR, Segade LAG and Fuentes I (2001). Muscle fibre types in the suprahyoid muscles of the rat. J. Anat. 198: 283294.

Daitoku H and Fukamizu A (2007). FOXO transcription factors in the regulatory networks of longevity. J. Biochem. 141: 769-774.

Fryer HJ, Davis GE, Manthorpe M, Varon S, et al. (1986). Lowry protein assay using an automatic microtiter plate spectrophotometer. Anal. Biochem. 153: 262-266.

Gross DN, van den Heuvel APJ and Birnbaum MJ (2008). The role of FoxO in the regulation of metabolism. Oncogene 27: 2320-2336.

Hemmings KM, Parr T, Daniel ZCTR, Picard B, et al. (2009). Examination of myosin heavy chain isoform expression in ovine skeletal muscles. J. Anim. Sci. 87: 3915-3922.

Horton MJ, Brandon CA, Morris TJ, Braun TW, et al. (2001). Abundant expression of myosin heavy-chain IIB RNA in a subset of human masseter muscle fibres. Arch. Oral. Biol. 46: 1039-1050.

Jankala H, Harjola VP, Petersen NE, Harkonen M, et al. (1997). Myosin heavy chain mRNA transform to faster isoforms 
in immobilized skeletal muscle: a quantitative PCR study. J. Appl. Physiol. 82: 977-982.

Jordan T, Jiang HB and Li H and DiMario JX (2005). Regulation of skeletal muscle fiber type and slow myosin heavy chain 2 gene expression by inositol trisphosphate receptor 1. J. Cell Sci. 118: 2295-2302.

Kamei Y, Miura S, Suzuki M, Kai Y, et al. (2004). Skeletal Muscle FOXO1 (FKHR) Transgenic Mice Have Less Skeletal, Muscle Mass, Down-regulated Type I (Slow Twitch/Red Muscle)Fiber Genes, and Impaired Glycemic Control. J. Biol.Chem. 279: 41114-41123.

Kitamura T, Kitamura YI, Funahashi Y, Shawber CJ, et al. (2007). A foxo/notch pathway controls myogenic differentiation and fiber type specification. J. Clin. Invest. 117: 2477-2485.

Lee B, Vermassen E, Yoon SY, Vanderheyden V, et al. (2006). Phosphorylation of $\mathrm{IP}_{3} \mathrm{R} 1$ and the regulation of $\left[\mathrm{Ca}^{2+}\right]$ responses at fertilization) a role for the MAP kinase pathway. Development 133: 4355-4365.

Lefaucheur L, Ecolan P, Plantard L, Gueguen N, et al. (2002). New insights into muscle fiber types in the pig. J. Histochem. Cytochem. 50: 719-730.

Lefaucheur L, Milan D, Ecolan P, Le Callennec C, et al. (2004). Myosin heavy chain composition of different skeletal muscles in Large White and Meishan pigs. J. Anim. Sci. 82: 1931-1941.

Lengerken G, Maak S, Wicke M, Fiedler I, et al. (1994). Suitability of structural and functional traits of skeletal muscle for the genetic improvement of meat quality in pigs. ARCH. Tierzuch. 37: 133-143.

Li Y, Xu ZY, Li HY, Xiong Y, et al. (2010). Differential transcriptional analysis between red and white skeletal muscle of Chinese Meishan pigs. Int. J. Biol. Sci. 6: 350-360.

Lin YQ, Zhuang HL and Yang GS (2007). Effects of RXR $\alpha$ gene silencing on the porcine adipocyte differentiation in vitro. Comp. Biochem. Physiol. Part D 2 2: 207-214.

Lucas CA, Kang LH and Hoh JF (2000). Monospecific antibodies against the three mammalian fast limb myosin heavy chains. Biochem. Biophys. Res. Commun. 272: 303-308.

Ni YG, Kambeez BJ, Wang N, Oh M, et al. (2006). Foxo transcription factors blunt cardiac hypertrophy by inhibiting calcineurin signaling. Circulation. 114: 1159-1168.

Pette D and Staron RS (2000). Myosin isoforms, muscle fiber types, and transitions. Microsc Res Tech. 50: 500-509.

Pette D and Staron RS (2001) Transitions of muscle fiber phenotypic profiles. Histochem. and Cell Biol. 115: 359-372.

Rogers NH, Perfield II JW, Strissel KJ, Obin MS, et al. (2010). Loss of ovarian function in mice results in abrogated skeletal muscle PPAR $\delta$ and FoxO1-mediated gene expression. Biochem. Biophys. Res.Commun. 392: 1-3.

Roy SK, Srivastava RK and Shankar S (2010). Inhibition of PI3K/AKT and MAPK /ERK pathways causes activation of FOXO transcription factor, leading to cell cycle arrest and apoptosis in pancreatic cancer. J. Mol. Signal. 5: 10.

Salih DA and Brunet A (2008). FoxO transcription factors in the maintenance of cellular homeostasis during aging. Curr. Opin. Cell. Biol. 20: 126-136.

Schiaffino S and Reggiani C (1996) Molecular diversity of myofibrillar proteins: gene regulation and functional significance. Physiol. Rev. 76: 371-423.

Shi H, Jason M S, Jonathan M P, Zeng C, et al. (2008). Modulation of skeletal muscle fiber type by mitogen-activated protein kinase signaling. FASEB. J. 22: 2990-3000.

Southgate RJ, Neill B, Prelovsek O, El-Osta A, et al. (2007). Foxo1 regulates the expression of 4e-bp1 and inhibits motor signaling in mammalian skeletal muscle. J. Biol. Chem. 282: 21176-21186.

Vadászová A, Hudecová S, Križanová O, Soukup T, et al. (2006). Levels of myosin heavy chain mRNA transcripts and protein isoforms in the fast extensor digitorum longus muscle of 7-month-old rats with chronic thyroid status alterations. Physiol. Res. 55: 707-710.

Van der Heide LP, Hoekman MFM and Smidt MP (2004). The ins and outs of FoxO shuttling mechanisms of FoxO translocation and transcriptional regulation. J. Biochem. 380: 297-309.

Vogt PK, Jiang H and Aoki M (2005). Triple layer control phosphorylation, acetylation and ubiquitination of FOXO proteins. Cell Cycle. 4: 908-913.

Vuocolo T, Byrne K, White J, McWilliam S, et al. (2007). Identification of a gene network contributing to hypertrophy in callipyge skeletal muscle. Physiol. Gen. 28: 253-272.

Wang YX, Zhang CL, Ruth T Y, Cho HK, et al. (2004). Regulation of Muscle Fiber Type and Running Endurance by PPARd. PLoS Biol. 2: 1532-1539.

Yang YJ, Pang WJ, Bai L, Yang GS, et al. (2008). Expression of FoxO1 mRNA in muscle tissue of Bamei, Landrace and Landrace x Bamei. Hereditas. 30: 185-189. 